\title{
Determining influence of different factors on production optimization by developing production scenarios
}

\author{
Mojtaba Izadmehr ${ }^{1} \cdot$ Amin Daryasafar $^{2} \cdot$ Puyan Bakhshi $^{2}$ (1) Rauf Tavakoli $^{2}$. \\ Mohammad Ali Ghayyem ${ }^{2}$
}

Received: 23 January 2017/Accepted: 16 April 2017/Published online: 24 April 2017

(C) The Author(s) 2017. This article is an open access publication

\begin{abstract}
Production optimization is defined as the process of maximizing oil production over the long term while minimizing total production costs. The overall goal is to achieve the optimum profitability from the well or field. In this process, the reservoir system can be considered as a multiple input-output system. In this complex system injection and production wells are known as inputs and outputs. The output of the system is often affected by various parameters consisting reservoir conditions, petrophysics, and PVT data. The optimization of the injector rates and number and installation of submersible pumps are the main issues which have been studied in this paper. Determining the factor with the highest influence on production is of great interest and value. The aim of this paper is to develop different scenarios until 2026 in which above factors are considered; therefore, by comparing these scenarios, the best plan can be selected according to these factors as a combination of different separate scenarios along with economical and other related issues. In this paper effect of drilling new wells is also studied. The optimized plan consisted of opening a certain producer after its work-over, performing work-over on two certain producers, installing down-hole pumps in five certain injectors, increasing and reducing the injection rates of two and three certain injectors, respectively, and drilling six new producers. This optimized plan shows a $13.44 \%$
\end{abstract}

Puyan Bakhshi

puyan.bakhshi1991@gmail.com

1 Department of Chemical and Petroleum Engineering, Sharif University of Technology, 11365-9465 Tehran, Iran

2 Ahwaz Faculty of Petroleum, Petroleum University of Technology, Ahwaz, P.O. Box 63431, Iran increase in recovery factor in comparison with the plan in which there are no injectors in the field.

Keywords Reservoir management · Production optimization - Development scenarios - Water injection · Gas injection

\section{Introduction}

In order to control operations to obtain the maximum possible economic recovery from a reservoir, reservoir management is exercised; a process which relies on use of financial, technological, and human resources, while minimizing capital investments and operating expenses to maximize economic recovery of oil and gas from a reservoir (Thakur 1996). The recovery of oil from subsurface reservoirs often requires the injection of water or gas to maintain reservoir pressure and to displace the oil from injectors to producers (Jansen 2011). However, other industrial methods can be used along with EOR methods in order to optimize the amount of production rate. The optimization of production from a field is the pursuit of production strategies that are more economically attractive, an effort which is usually based on reservoir simulation. Control of the recovery process is through prescribing time-varying pressures or flow rates in the wells. Efficient methods used to optimize the recovery strategy make use of gradients of an economic objective function with respect to the well controls at every time step. In general, water injection, alleviating the effect of high water cut wells, electrical submersible pumps, gas injection, and drilling new wells are different operations which are used in order to increase the recovery factor of a reservoir. 
Water injection, the most commonly used method of IOR, usually suffers from reduced efficiency due to reservoir heterogeneity and increased cost associated with water recycling and handling. Optimal rate allocation to the injectors and producers can highly increase water flooding efficiency (Alhuthali et al. 2007; Almeida et al. 2007; Grinestaff 1999; Sudaryanto and Yortsos 2000). Through optimal rate control, we can manage the propagation of the flood front, delay water breakthrough at the producers, and also increase the recovery efficiency. Furthermore, an injection/production balance must be in place to keep a reasonable formation pressure (Liu et al. 2009; Zou et al. 2011).

High water cut problem is observed in producers in secondary and tertiary recovery operations. Accurate testing of such wells is important to improve oil and gas production and/or reduce water production. This problem can be dealt with by using various methods, e.g., closing high water cut perforations (Jaramillo et al. 2010; Waddell and Berthelet 2008).

Conventional submersible electric systems can economically and efficiently be used to lift the fluids from a well and to provide simultaneous surface injection pressure to meet the requirements of most water flood applications (O'Neil 1976).

Gas injection is frequently exercised as a secondary recovery method with the purpose of pressure maintenance and returning the initial production conditions by not only increasing the reservoir energy but also displacing the oil toward producers (Abbasi et al. 2010; Kalam et al. 2011).

Drilling new wells is also an important practice for influencing recovery factor and cumulative oil production, which can be considered as the most important one in this study.

Various tools are generally used to optimize oil production. Barnes et al. (1990) used incremental gas-oil ratio theory to develop a model for maximizing oil production and minimizing gas processing requirement. Lo et al. (1995) found a linear programming model that allot flow rate of wells when different constraints are present. Stoisits et al. (1994) used neural network and genetic algorithm to solve gas lift optimization with various gas constraints (Ragavanpillai 2012). Most of the studies on operational optimization have concentrated on the effect of a single parameter influencing production, and there have been few studies that have combined different methods (Stoisits et al. 1999; Tunio et al. 2011).

This study aims to develop an optimization model which would be an improvement over the current model. The objective of this work is to optimize the target factors of cumulative oil production, oil production rate, and cumulative injection of water/gas by modifying parameters such as water/gas injection rate, the number and location of new injectors and producers, performance of the existing wells, and bottom-hole pressure. This required the development of a field production model which included well performance, injection optimization, drilling new wells, i.e., producers and injectors, and modifying wells. It is really important to determine the effects of different factors on oil production; therefore, each factor is investigated in a separate scenario, and the best optimization scenario is presented as a combination of other factors. The optimized plan was achieved by taking the following measures: opening a certain well (E2W2P) after its work-over while closing high water cut interval at end of its drain, performing work-over on two certain wells (E2P3c and E3P5), installing down-hole pumps in five certain wells (E1P1, E1P2, E1P4wo, E2P2, E3P1, and E3P5), reduction in the injection rates of three certain wells (E3W1, E3W4, and E1W2), increasing the injection rates of two certain wells (E2W3 and E3W2), drilling six new producers (PN1a, PN3a, PN3b, PN4, PN5, and PN6), and putting no limits on gas production.

\section{Full-field model}

The full-field model up-scaled from the geological model of one of the oil reservoirs in the Middle East has cornerpoint grid (CPG) geometry. The selected horizontal cell size is $100 \times 100 \mathrm{~m}$, and the model has 14 vertical simulation layers. The number of active cells is around 133,168 for the full-field model. Input parameters come from phase 2 of the study and from the phenomenological studies. STOIP of the simulation model is $0.9 \%$ higher than in the geological model which is acceptable. The final match was obtained after about 300 runs. The main constraints relevant to production forecast are as follows:

- Max field oil production rate: 100,000 STB/D.

- Max field water production rate: 25,000 BBL/D.

- Max field gas production rate: $108 \mathrm{MMSCF} / \mathrm{D}$.

- Max water injection facilities capacity: 160,000 BBL/ D.

The schematic figure of this field which contains the location of all the wells (both existing and proposed in the following scenarios) is shown in Fig. 1.

\section{Prediction scenarios}

A base case scenario was designed on the basis of production forecast of the existing wells in one of the oil reservoirs in the Middle East that are producing at the end of the history. Fourteen wells have been producers, and 12 wells were water injectors during the history. The base case 


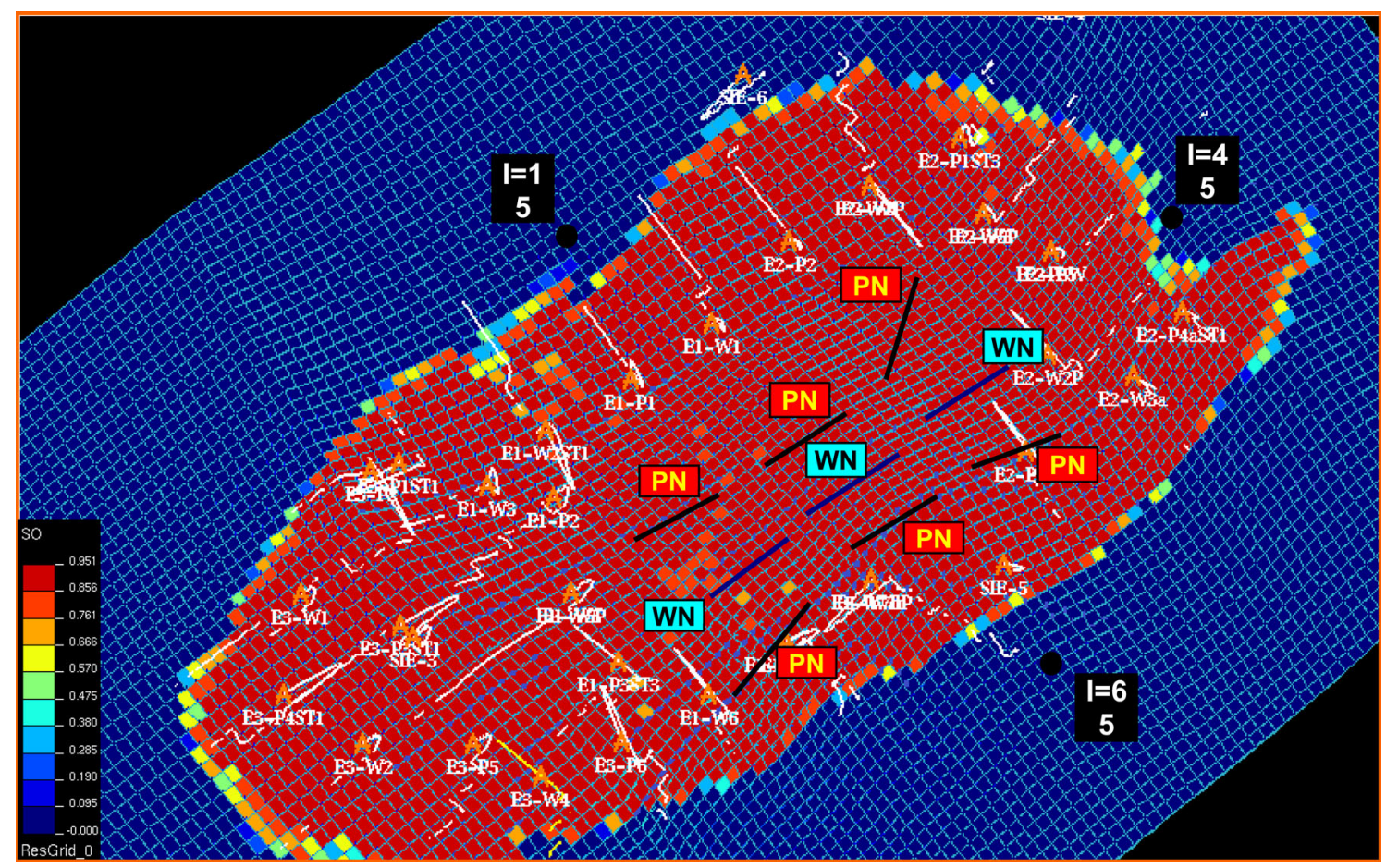

Fig. 1 Location of the wells in the field

scenario is run until 2026 and is a basis for comparison with the results of the alternative development cases.

A number of ten prediction scenarios have been set up and run as alternative development cases. The optimization of the injector rates, installation of submersible pumps, and drilling of new producers and injectors are the main issues which have been investigated to identify the potential optimum scenarios. All of these scenarios were run until 2026, and their descriptions are as follows:

\section{Scenario\#1}

In this case, all of the injectors are closed. This was done to investigate the impact of injectors on the pressure support of the reservoir.

\section{Scenario\#2}

In scenario 2 the injection rates of wells E3W1 and E3W4 are reduced from 9202 and 4417 to $1000 \mathrm{BBL} / \mathrm{D}$, and water injection rate of well E2W3a is increased from 6488 to $10,000 \mathrm{BBL} / \mathrm{D}$.

\section{Scenario\#3}

In this scenario the injection rates of wells E3W1, E3W4, and E1W2ST1 after several trials and analysis of the results are reduced from 9202, 4417, and 12,016 BBL/D to 1000, 1500 , and $8000 \mathrm{BBL} / \mathrm{D}$, respectively. Furthermore, the water injection rate of well E2W3a is increased from 6488 $\mathrm{BBL} / \mathrm{D}$ to $14,000 \mathrm{BBL} / \mathrm{D}$.

\section{Scenario\#4}

In this scenario by assuming water injection efficiency of about $90 \%$, the water injection rate was increased from $112,000 \mathrm{BBL} / \mathrm{D}$ to $140,000 \mathrm{BBL} / \mathrm{D}$.

\section{Scenario\#5}

In this scenario field injection rates were increased up to $160,000 \mathrm{BBL} / \mathrm{D}$ assuming installation of new pumps in the field.

\section{Scenario\#6}

Water cut can be measured by various methods including ERCB and NEXEN (Waddell and Berthelet 2008). In this scenario, seven high water cut wells were selected and their perforations at the end of their drain were closed. This can practically be done using cement plugs at end of drain for horizontal wells in this field.

\section{Scenario\#7}

In this scenario all producers are equipped with submersible pumps to lift fluids from a well and to provide simultaneous surface injection pressure. Hence, the 


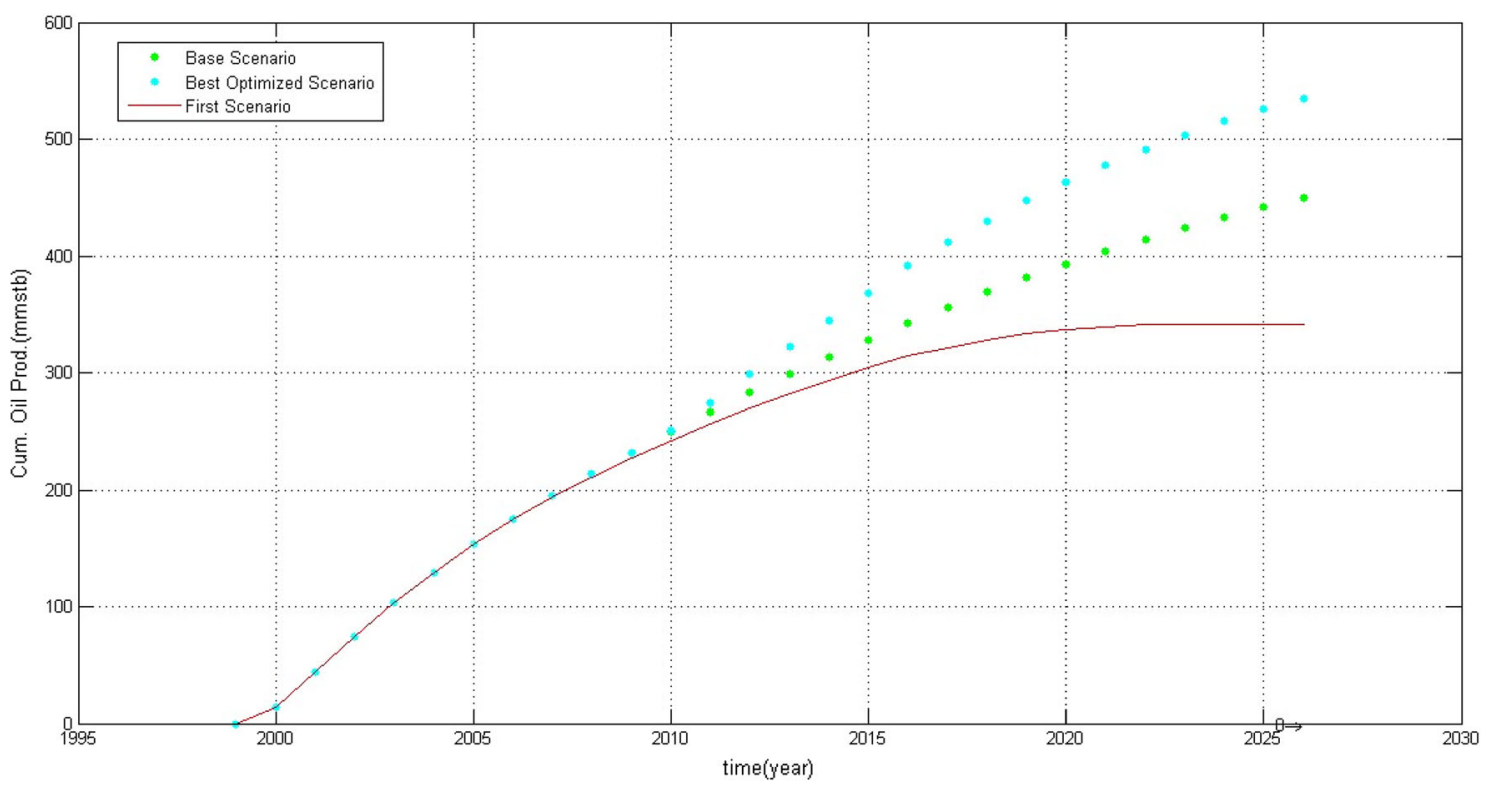

Fig. 2 Cumulative oil production of first scenario

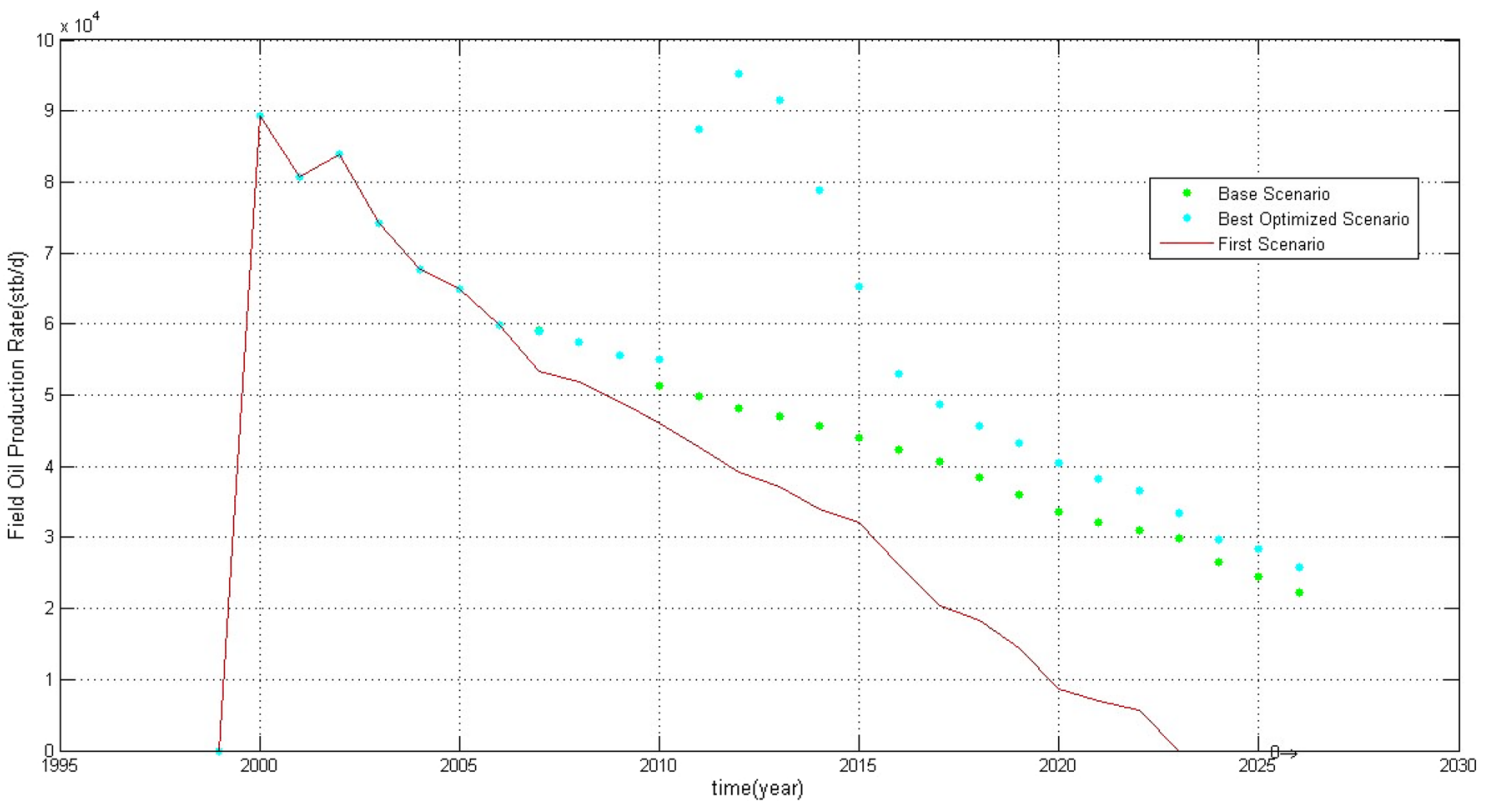

Fig. 3 Field production rate of first scenario

bottom-hole pressure limit is decreased from 2250 to 1900 psia, and the maximum well oil rate constraint is set to 1.5 and thus the oil production rate at the time of pump installation.

\section{Scenario\#8}

Another prospect for increasing oil recovery arises from drilling new wells in the field. Drilling new wells must be in line with the client's policy and also limitations present in the field. After reviewing oil saturation maps at the end of history, six areas were selected which remained undrained and are suitable for drilling of six new producers and three new injectors. The location map for these new wells is presented in Fig. 1. Based on this concept a scenario was designed and run up to 2026.

\section{Alternates of Scenario\#8}

1. In this scenario wells PN2a, PN1b, and PN2b which were not beneficial were excluded. Also remove all injectors. 


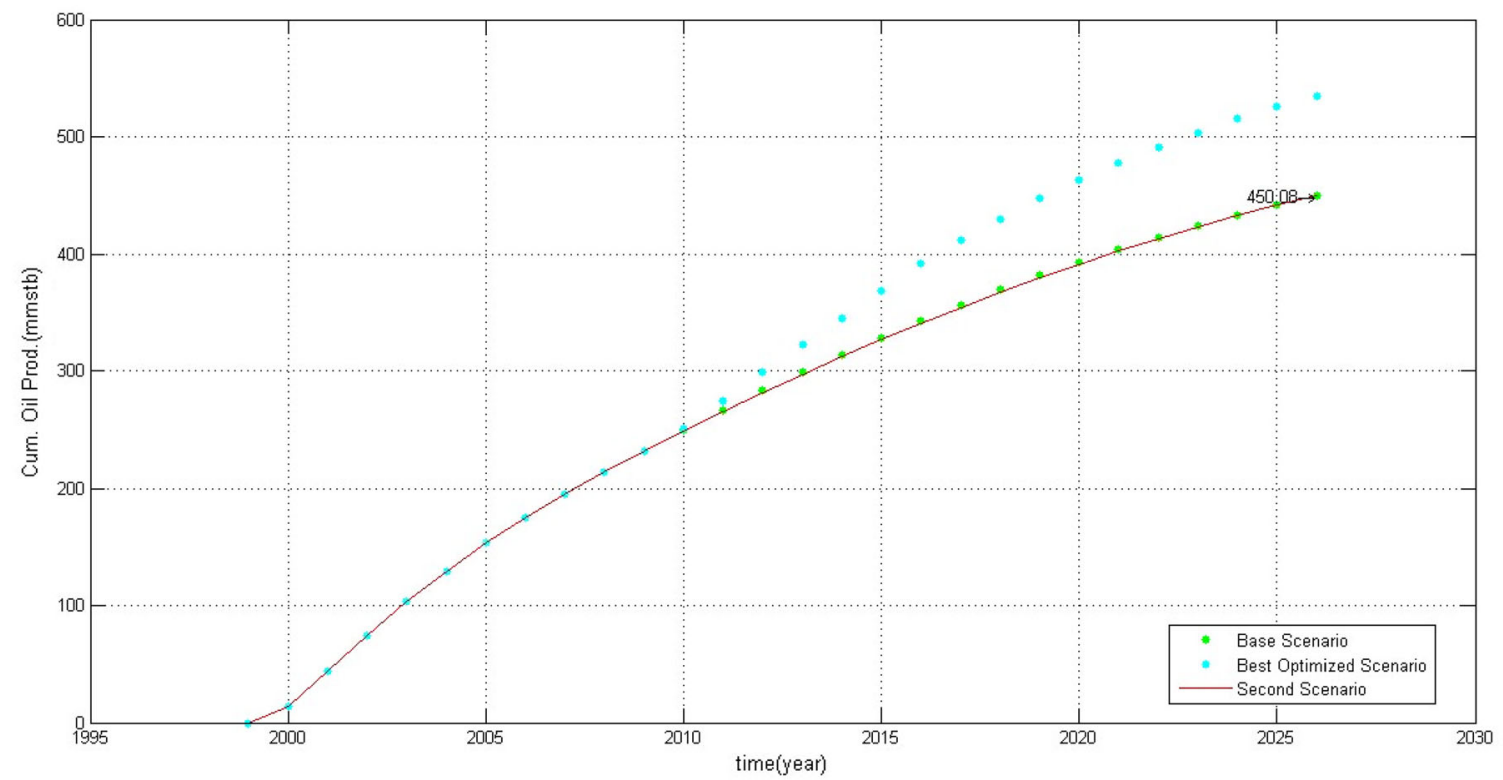

Fig. 4 Cumulative oil production of second scenario

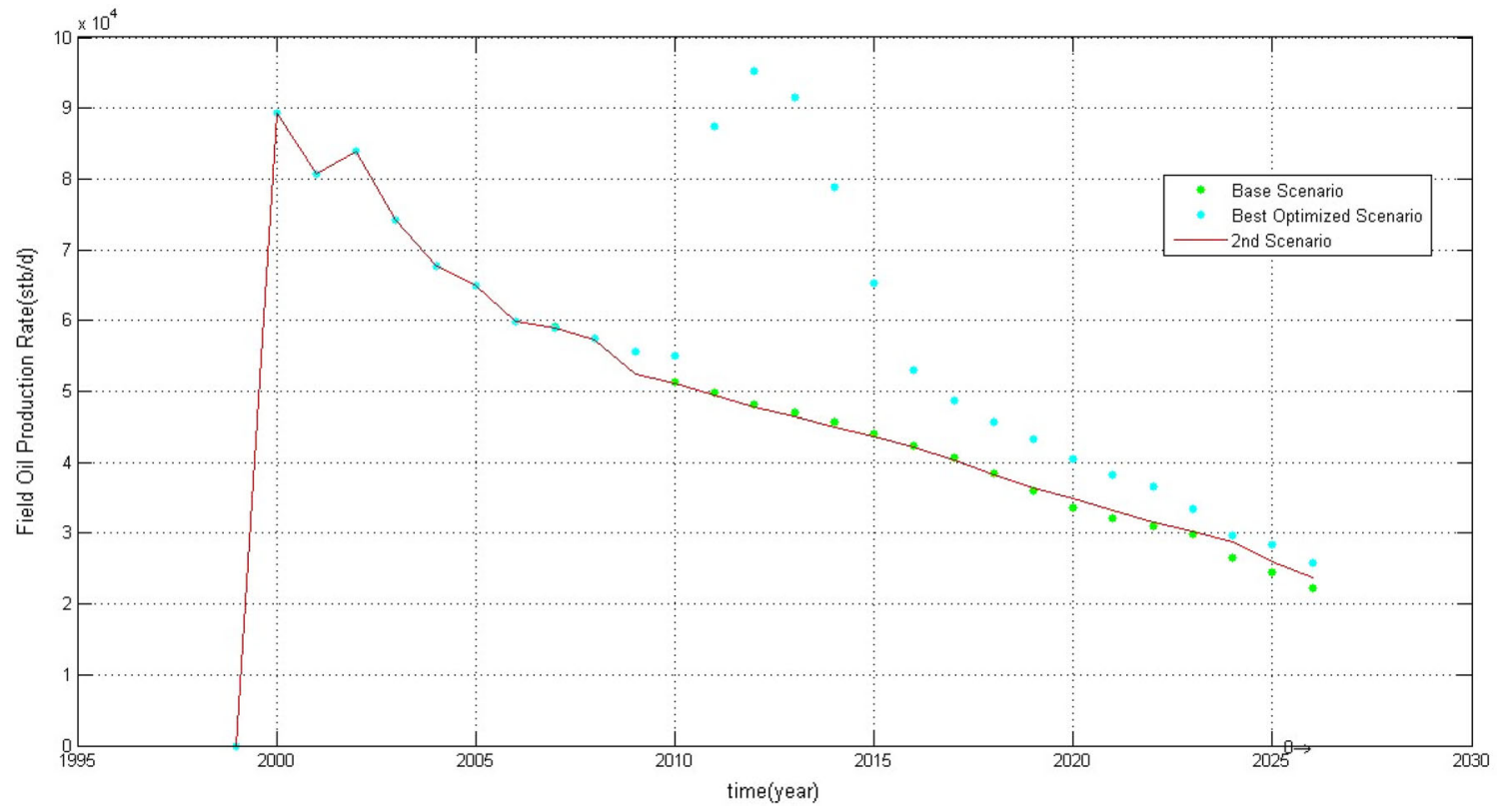

Fig. 5 Field production rate of second scenario

2. This scenario is similar to scenario a, except that well PN2a is added as an injector.

3. This scenario is similar to scenario a, except that well PN4 is added as a producer.

4. This scenario is similar to scenario a, except that well PN5 is added as a producer.

5. This scenario is similar to scenario a, except that well PN6 is added as a producer.

\section{Scenario\#9}

Gas injection is being increasingly applied as a secondary or tertiary oil recovery process, particularly in reservoirs with a reasonable dip angle, preferably of high permeability and containing light oil. In this scenario three gas injectors, i.e., SIE3, SIE5, and E2P5, were added to the model. 


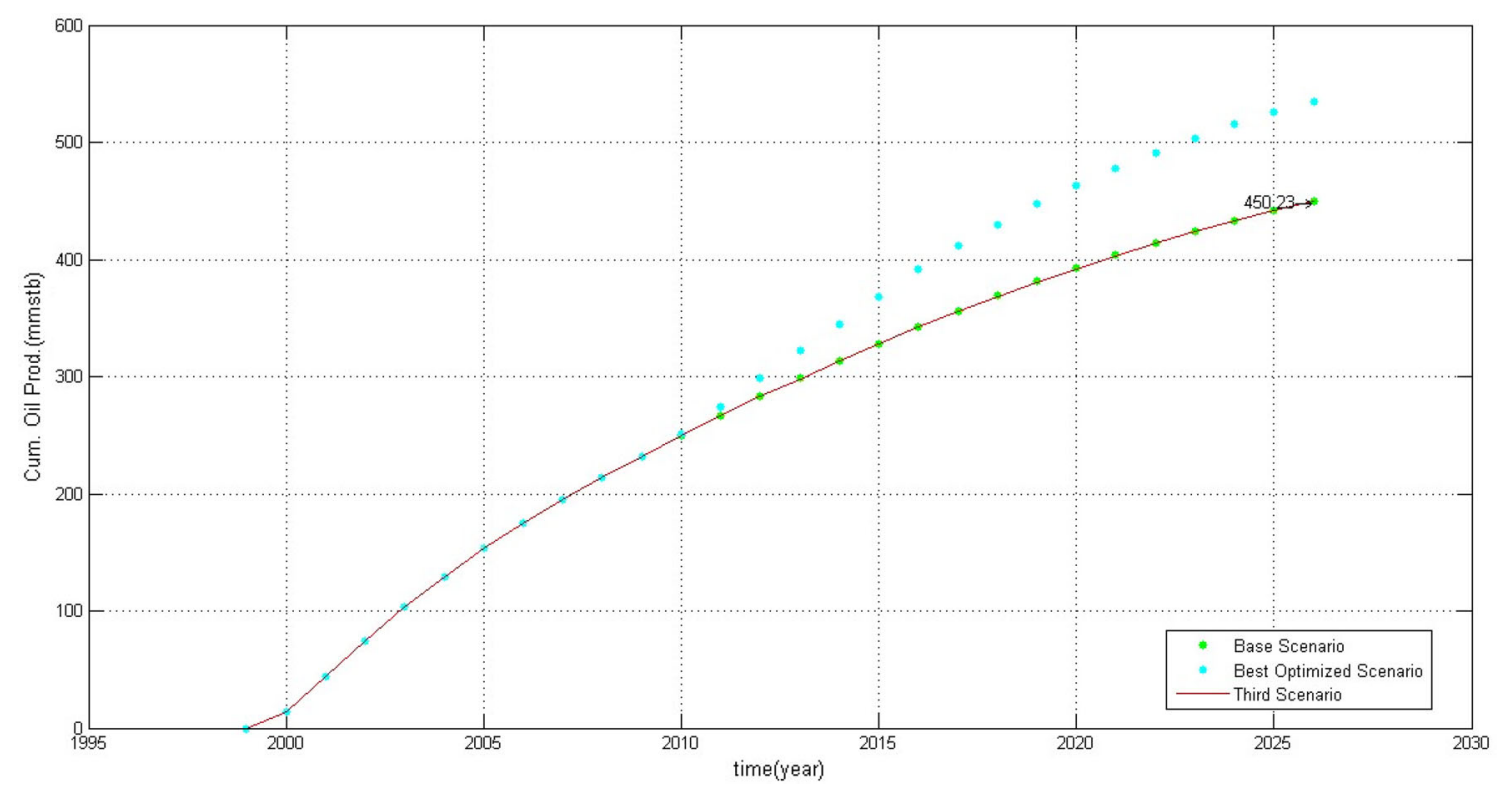

Fig. 6 Cumulative oil production of third scenario

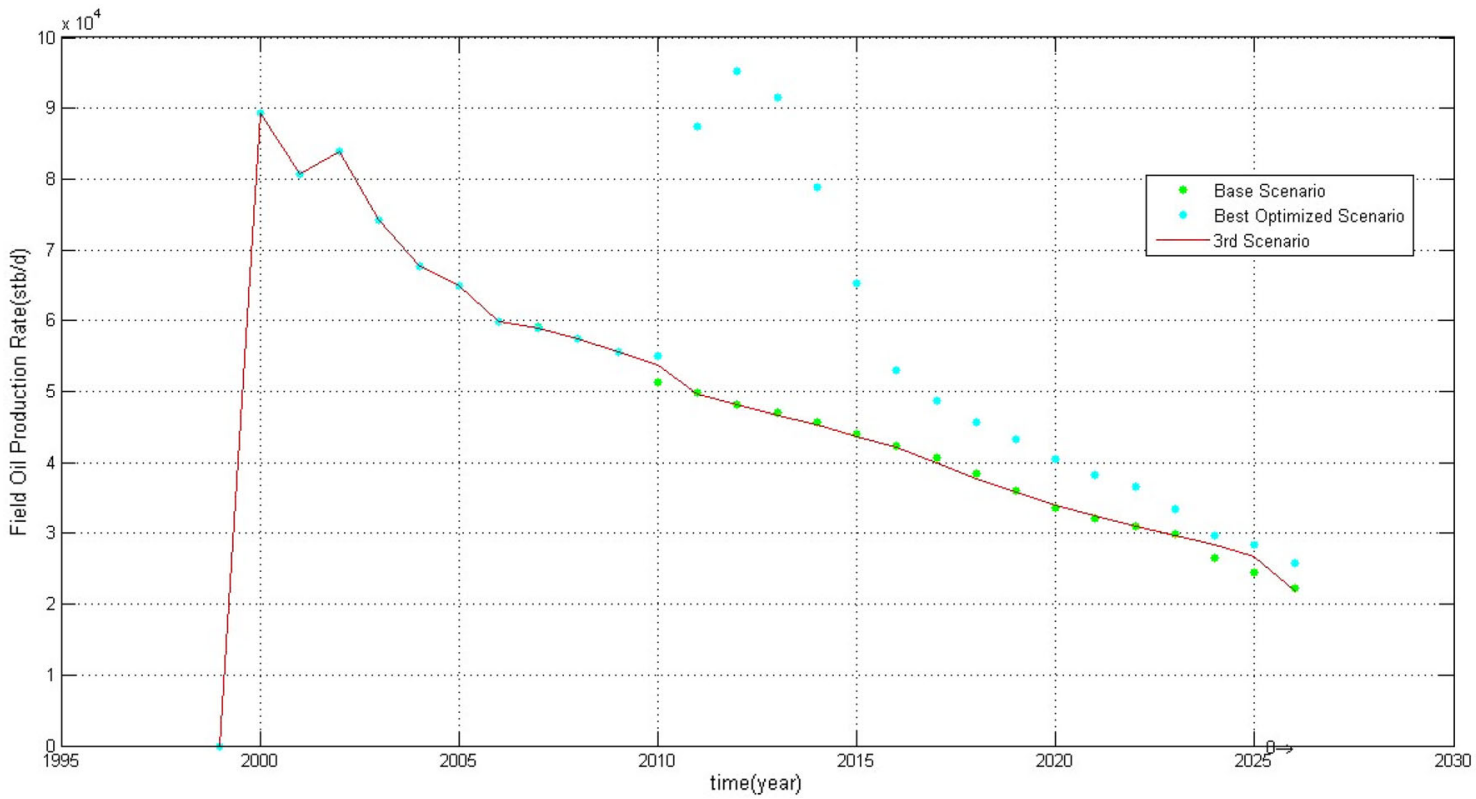

Fig. 7 Field production rate of third scenario

\section{Scenario\#10}

Since each separate parameter has certain effects on the production, the best method of optimization should be selected as the best combination of all different methods, with the least cost and the highest efficiency. In this scenario, which is believed to be the optimal one among the cases proposed in this work, the following measures as a combination of other methods were taken:

- Opening Well E2W2P after its work-over (closing high water cut interval at end of its drain).

- Work-over wells E2P3c and E3P5 by closing the high water cut interval at the end of their drain.

- Installing down-hole pumps in wells E1P1, E1P2, E1P4wo, E2P2, E3P1, and E3P5. 


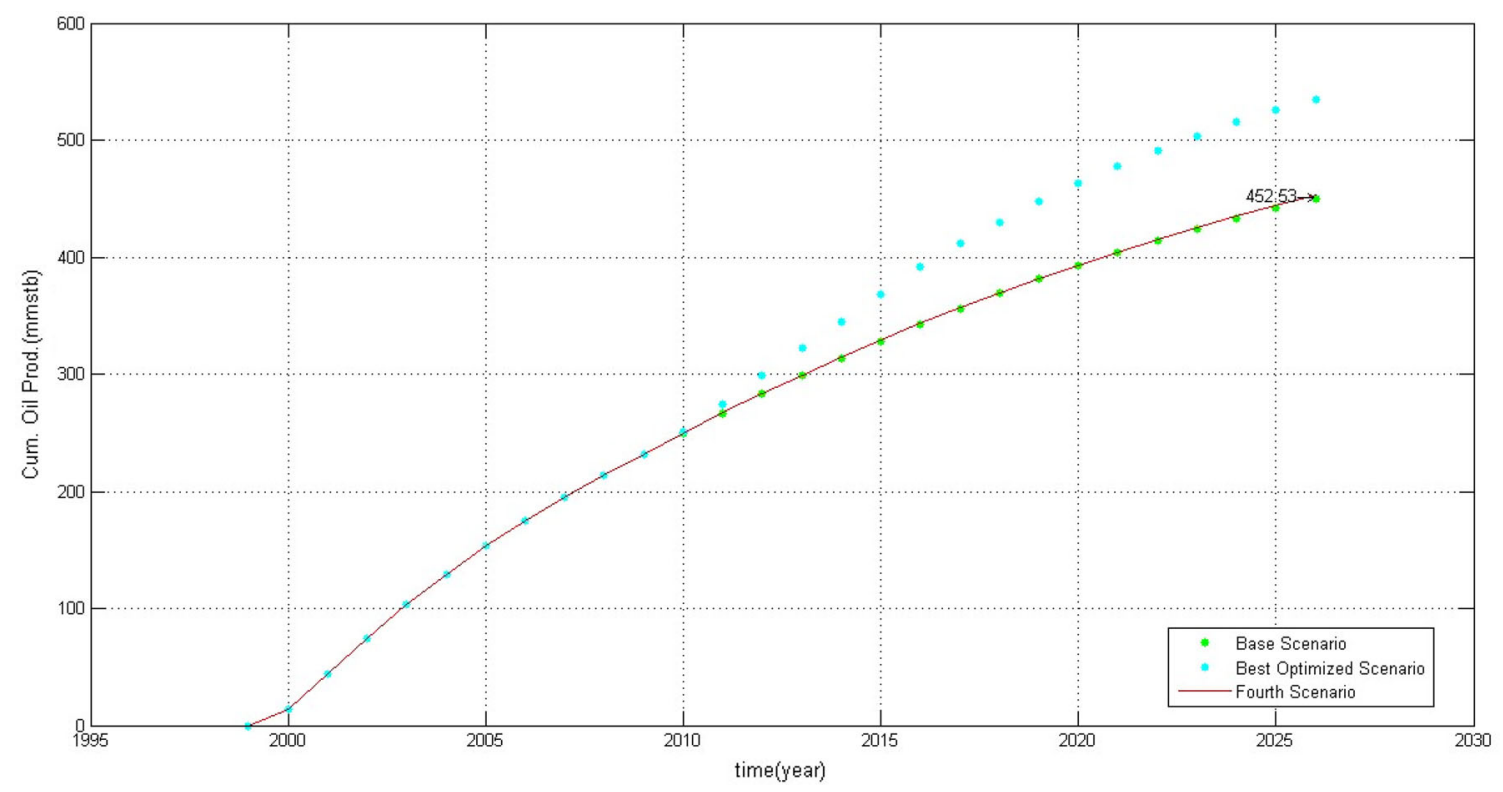

Fig. 8 Cumulative oil production of fourth scenario

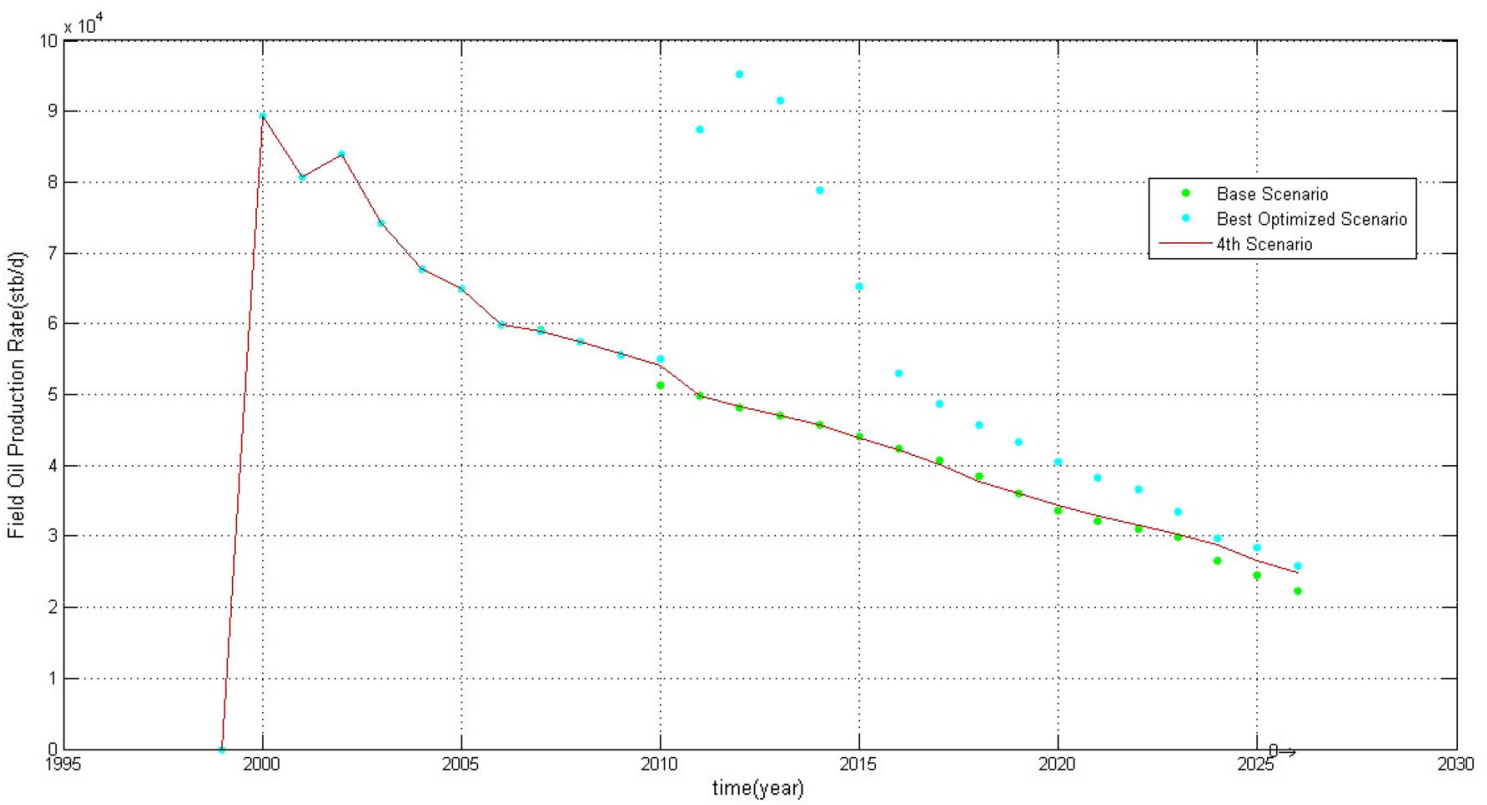

Fig. 9 Field production rate of fourth scenario

- Reducing the injection rate of the wells E3W1, E3W4, and E1W2 from 9202, 4417, and 1216 BBL/D to 1000, 1500 , and $8000 \mathrm{BBL} / \mathrm{D}$, respectively, and increasing the injection rate of wells E2W3 and E3W2 from 6488 and $10,301 \mathrm{BBL} / \mathrm{D}$ to 14,000 and $18,000 \mathrm{BBL} / \mathrm{D}$, respectively.

- Drilling six new producers PN1a, PN3a, PN3b, PN4, PN5, and PN6 as presented earlier.

- No gas production limit was considered in this scenario.

\section{Results and discussion}

\section{Base case scenario}

Based on the obtained results, the total off-take from the reservoir is less than the volume of the injected water. Also it can be observed that none of the oil, water and gas productions reach the constraint limits at the base case scenario. 


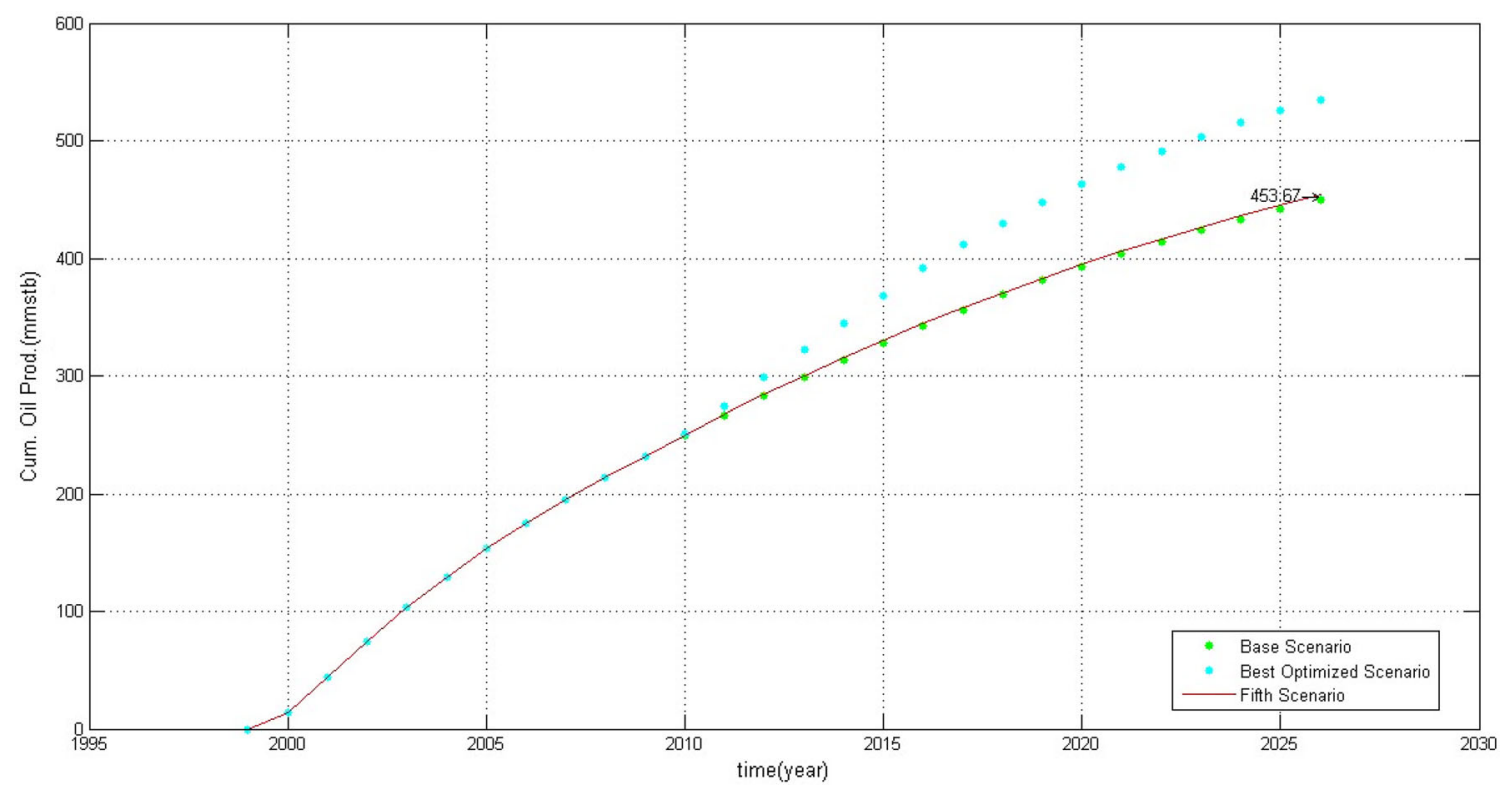

Fig. 10 Cumulative oil production of fifth scenario

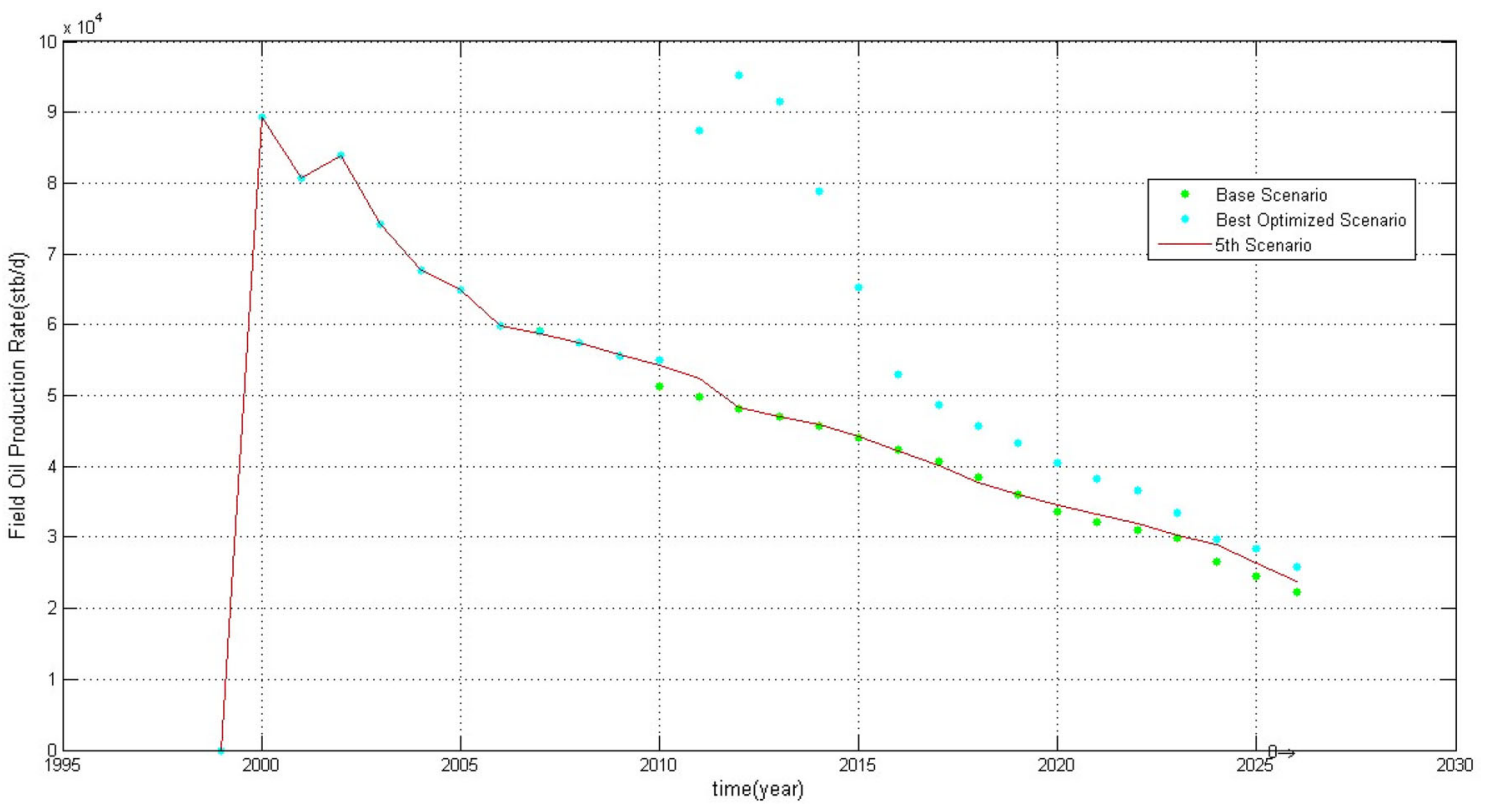

Fig. 11 Field production rate of fifth scenario

\section{Alternative development cases}

These cases have been selected for discussion herein as follows:

\section{Scenario\#1}

The results are presented in Fig. 2. As it is shown, closing of the injectors has a significant impact on reducing the oil production. This is due to the lack of pressure support and also inefficient oil sweeping. Figures 2 and 3 compare this scenario with the base case and the optimum scenario. Noticeable reduction in both cumulative oil production and production rate starts from 2010. Cumulative oil production will be 107.74 MMSTB less than the base scenario in the year 2026 having fixed on the constant value of 341.25 MMSTB from 2023. According to Fig. 3, oil production rate will reduce from 89,337 STB/D in the year 2000 to $5752 \mathrm{STB} / \mathrm{D}$ in the year 2022. Figure 2 shows the great importance of using water injectors. 
Table 1 Production statistics at the end of prediction period (2026) for scenarios 1-5

\begin{tabular}{llccc}
\hline Scenario & $\begin{array}{l}\text { Cum. oil production } \\
\text { (MMSTB) }\end{array}$ & $\begin{array}{l}\text { Cum. water production } \\
\text { (MMSTB) }\end{array}$ & $\begin{array}{l}\text { Cum. water injection } \\
\text { (MMBBL) }\end{array}$ & $\begin{array}{l}\text { Recovery factor } \\
\% \text { OOIP }\end{array}$ \\
\hline Base case scenario & 449.33 & 109.01 & 826.5 & 30.44 \\
Scenario\#1 & 341.56 & 43.88 & 217.33 & 22.82 \\
Scenario\#2 & 450.08 & 108.61 & 796.46 & 30.49 \\
Scenario\#3 & 450.23 & 118.43 & 834.88 & 30.50 \\
Scenario\#4 & 452.53 & 125.25 & 982.1 & 30.75 \\
Scenario\#5 & 453.67 & 128.38 & 1034.56 & 30.88 \\
\hline
\end{tabular}

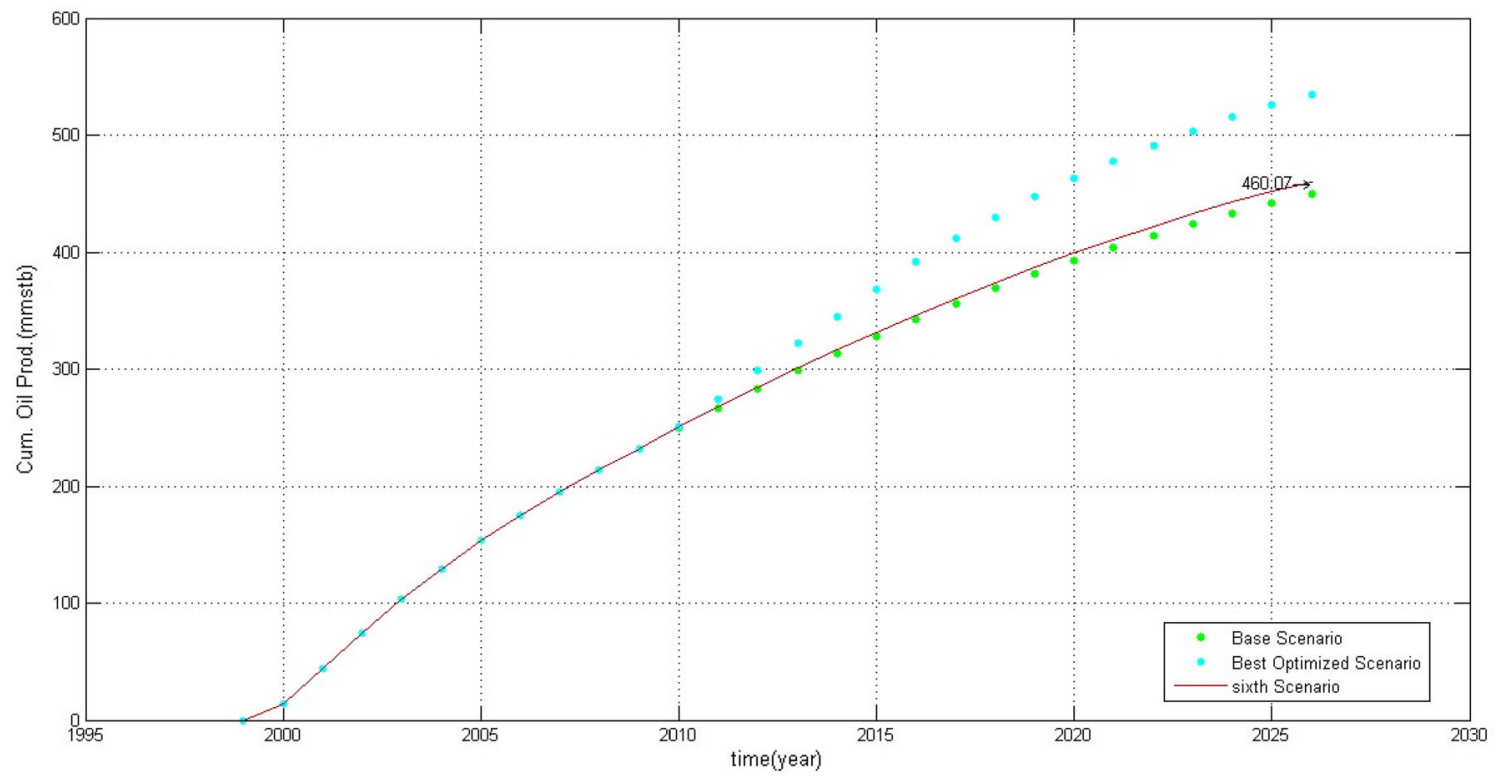

Fig. 12 Cumulative oil production of sixth scenario

\section{Scenario\#2}

In the previous scenario, it was shown that closing all injectors would have a great influence on the production; however, a more detailed relationship is investigated in scenarios $2-5$. The results of scenario 2 are presented in Figs. 4 and 5. Water injection rate has a total reduction of $8107 \mathrm{BBL} / \mathrm{D}$, but the cumulative oil production has increased 780 MSTB, illustrating the injection optimization to be a function of both water injection flow rate and the location of injectors. In an economical plan the location of injectors and flow rate of each one should be determined precisely, and it should be noted that the best plan is not necessarily the one with the highest injection rate. However, the production rate in Fig. 5 might not show a great deviation from the base scenario; nonetheless, it should be considered that, even this little increase in production will lead to a profit of more than 80 million dollars.

\section{Scenario\#3}

The results are presented in Figs. 6 and 7. This scenario as well includes a drop in the injection rate, which is a value of $7623 \mathrm{BBL} / \mathrm{D}$, while the cumulative oil production is 150 MSTB higher than that of scenario 2. A 7623 BBL/D decrease in water injection rate can be deemed an economical amount in comparison to a total injection rate of 112,000 BBL/D.

\section{Scenario\#4}

The results are presented in Figs. 8 and 9. This 28,000 BBL/D increase in water injection will lead to an overall 3230 MSTB cumulative oil production.

\section{Scenario\#5}

The results are presented in Figs. 10 and 11. This 48,000 BBL/D increase in water injection led to an overall 4370 


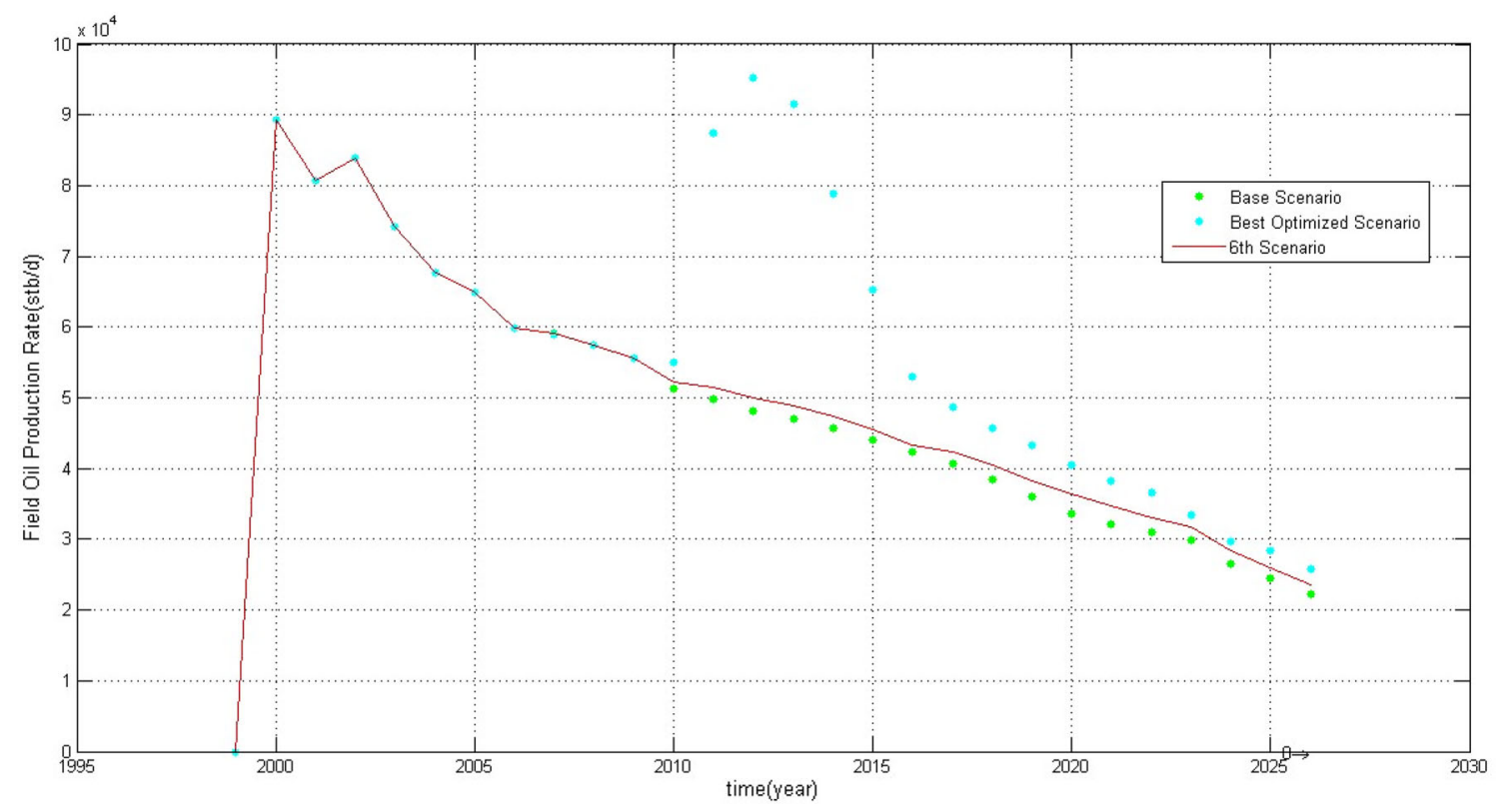

Fig. 13 Field production rate of sixth scenario

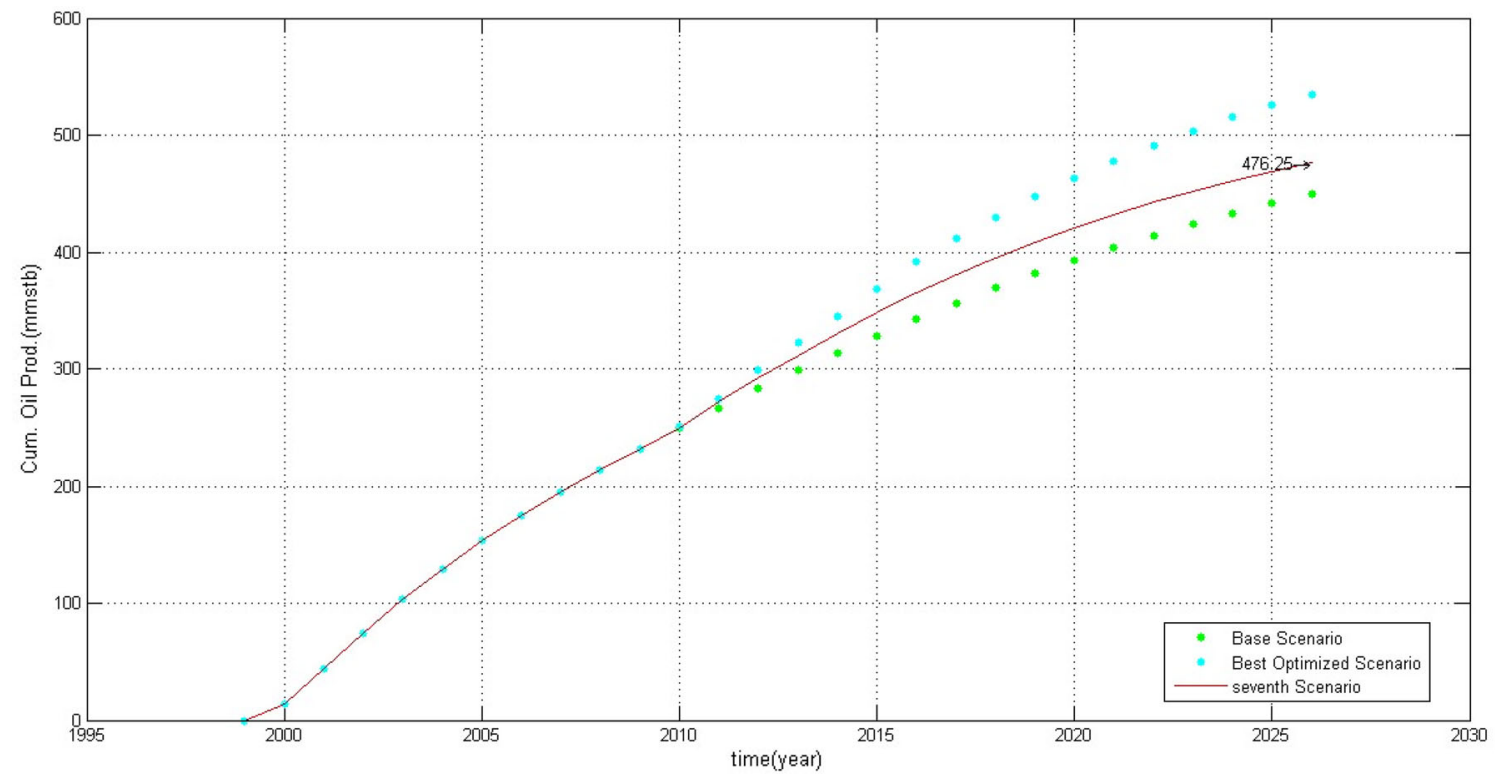

Fig. 14 Cumulative oil production of seventh scenario

MSTB cumulative oil production. Increasing water injection rate above this value does not seem economical.

\section{Comparison of the optimized injectors and injection rates}

As presented earlier, scenarios 1-5 investigate the optimization of injector rates. For cumulative water injection in the range of 700-1100 MMSTB, recovery factor shows to have a linear relationship with water injection rate; in other words, the more cumulative water injection, the higher the recovery factor. Nevertheless, injecting more than the aforementioned value is not advised. Additionally, the injection rate is not the only effective parameter. Tarr and Heuer (1962) showed that various factors including recovery mechanism, formation volume factor, crude oil viscosity, relative permeability, permeability distribution, and fractures influence the optimum time to start water injection. These factors were considered while trying to acquire the optimum scenario through water injection along with contemplating the economic aspects such as 


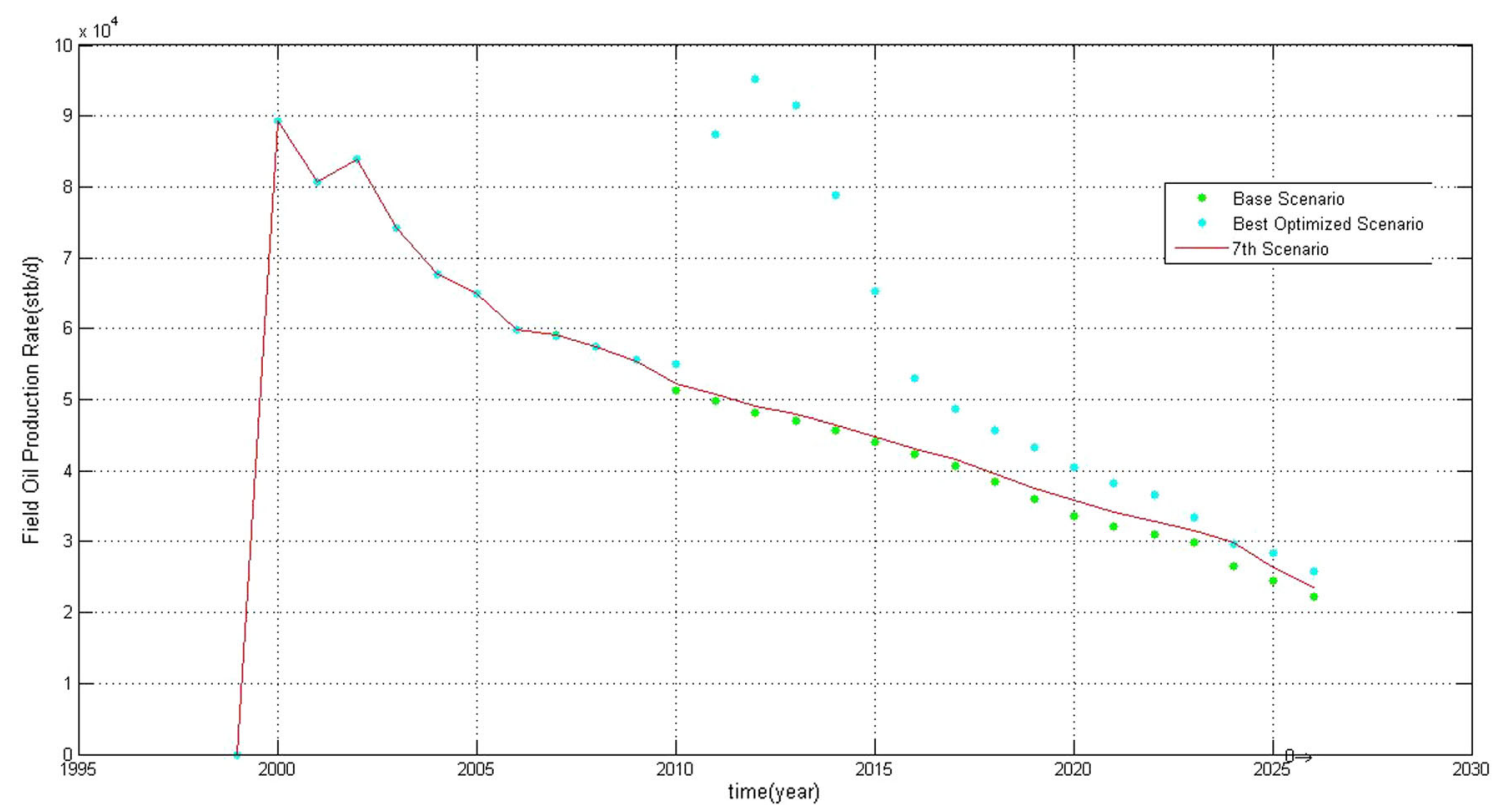

Fig. 15 Field production rate of seventh scenario

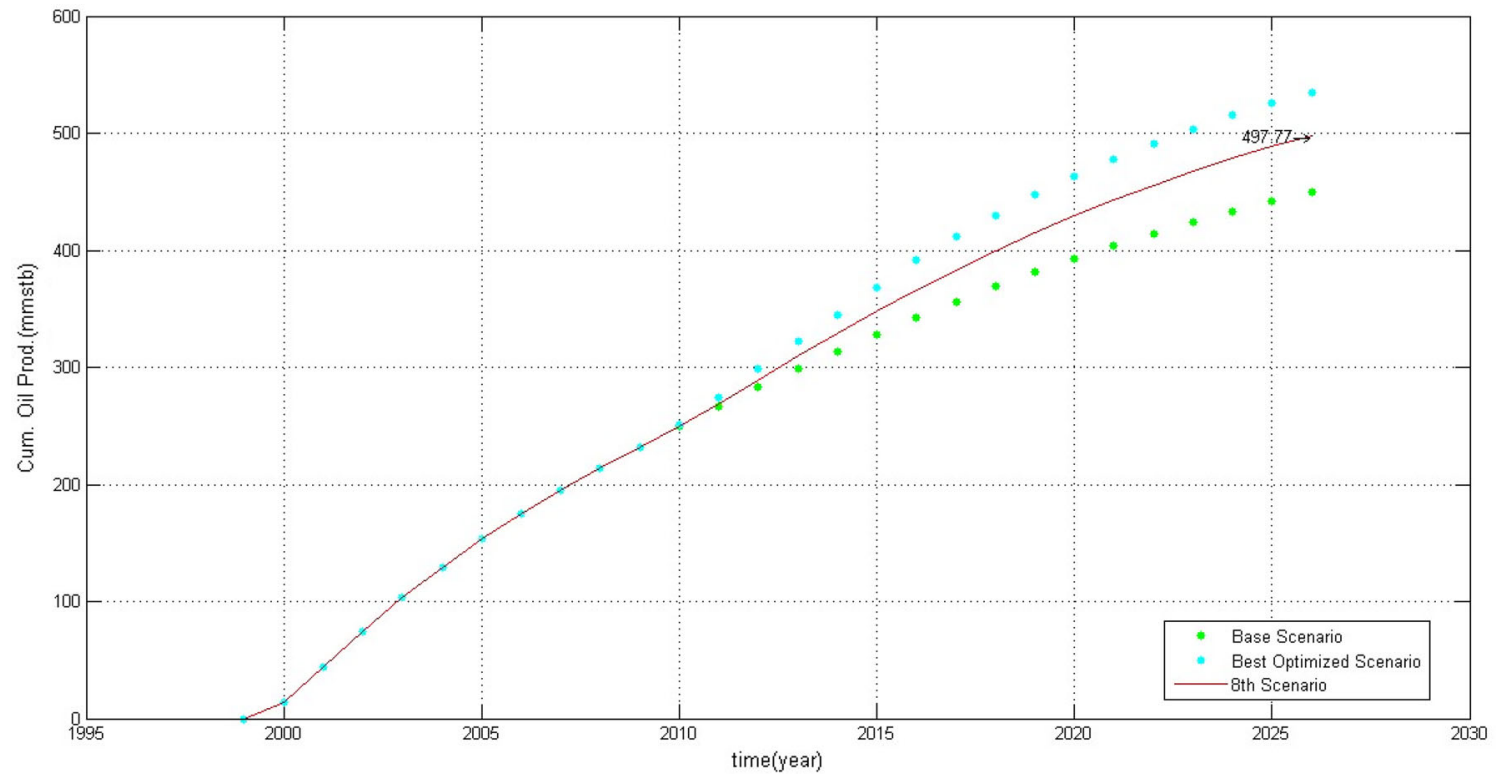

Fig. 16 Cumulative oil production of eighth scenario

reliability, minimum cost, and maximum production (Palsson et al. 2003); however, it does not seem to be the best method for increasing the recovery factor. Results of scenarios 1-5 are compared in Table 1.

\section{Scenario\#6}

The results are presented in Figs. 12 and 13. The summary of the results of this run is presented below. As can be seen, closing the high water cut perforations yields a good increment in the oil recovery and in the oil production as well. Closing perforations of high water cut wells gives better results than water injection.

\section{Scenario\#7}

In this scenario, the bottom-hole pressure limit was decreased from 2250 to 1900 psia and the maximum well oil rate constraint was set to 1.5 . The results are presented in Figs. 14 and 15. 


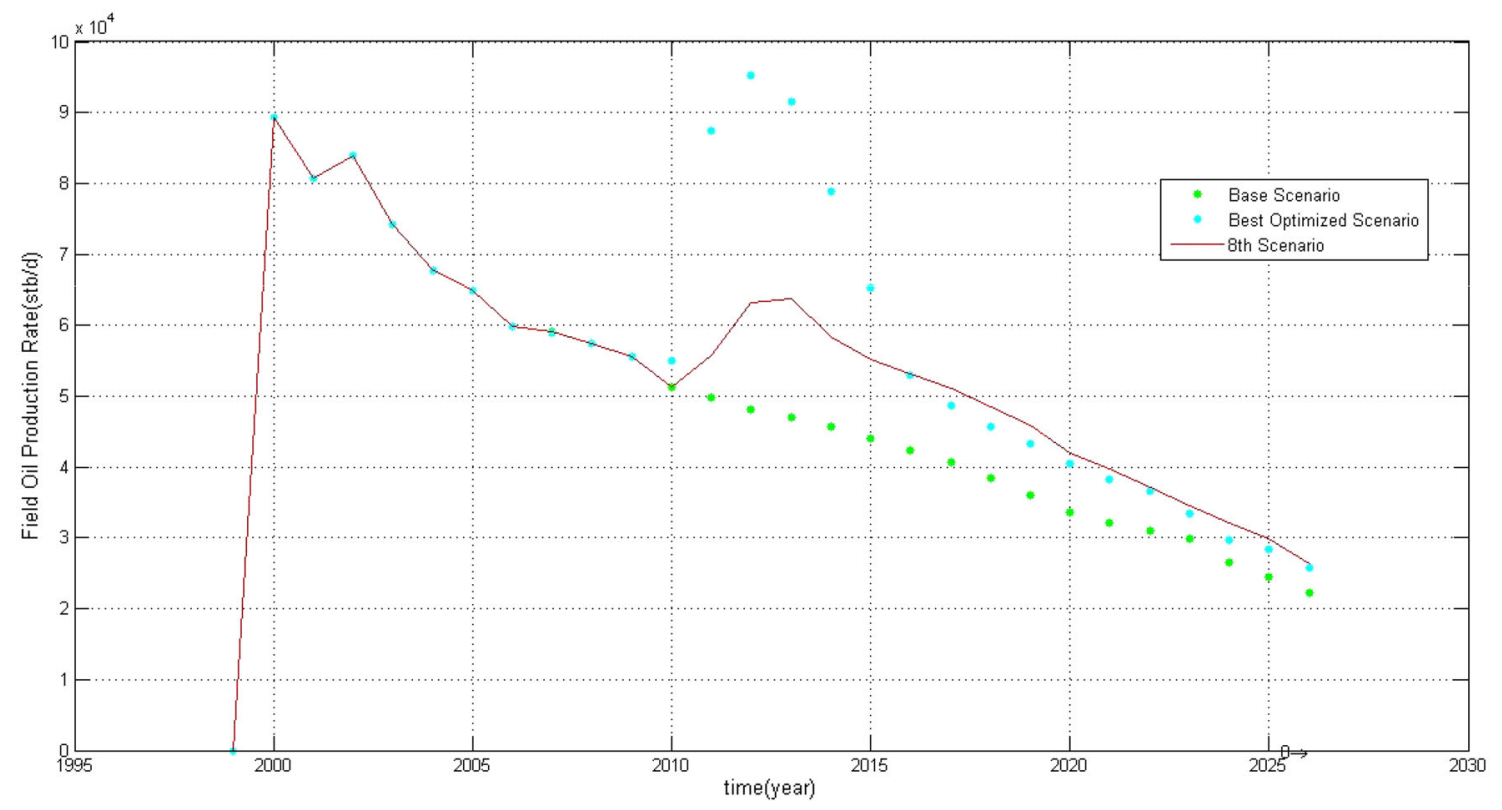

Fig. 17 Field production rate of eighth scenario

Table 2 Production statistics at the end of prediction period (2026) for scenarios 8-8e

\begin{tabular}{lllll}
\hline Scenario & $\begin{array}{l}\text { Cum. oil production } \\
\text { (MMSTB) }\end{array}$ & $\begin{array}{l}\text { Cum. water production } \\
\text { (MMSTB) }\end{array}$ & $\begin{array}{l}\text { Cum. water injection } \\
\text { (MMBBL) }\end{array}$ & $\begin{array}{l}\text { Recovery factor } \\
\% \text { OOIP }\end{array}$ \\
\hline Base case scenario & 449.33 & 109.01 & 826.5 & 30.44 \\
Scenario\#8 & 497.77 & 111.67 & 866.4 & 33.77 \\
Scenario\#8a & 486.47 & 98.99 & 777.05 & 32.92 \\
Scenario\#8b & 491.64 & 117.85 & 813.3 & 33.28 \\
Scenario\#8c & 498.26 & 111.1 & 813.3 & 33.75 \\
Scenario\#8d & 507.61 & 113.78 & 813.3 & 34.42 \\
Scenario\#8e & 515.96 & 113.28 & 813.3 & 34.97 \\
\hline
\end{tabular}

\section{Scenario\#8}

The results of the main Scenario\#8 which contained drilling of six new producers and three new injectors are presented in Figs. 16 and 17.

\section{Comparison of drilling new wells in different scenarios}

As mentioned earlier, the scenarios 8-8e were designed and run to optimize drilling of new wells. Table 2 presents the summary of the results.

Drilling new wells seems to have a much greater effect on increasing recovery factor than does optimizing injection flow rates. The highest RF in flow rate optimization of injection wells was $30.88 \%$, whereas drilling new wells increased RF to an average value of $33.85 \%$. This field still shows to have great potential in drilling, and as some undrained areas can still be found, new wells are the best method to extract the remaining oil.

\section{Scenario\#9}

The results are presented in Figs. 18 and 19. Gas injection is not suggested as a certain separate optimization plan in this field. This is due to the fact that there has not been a gas injector in this field; thus, new gas injectors should be added to injection production system which has a considerable cost. On the other hand, this increase in the cumulative oil production can be achieved by optimizing water injection which is much less expensive as the injectors are already drilled in the field.

\section{Scenario\#10}

According to the previous discussions, including each separate parameter which affects the production, the best method of optimization was selected as the best combination of all different methods, with the least cost and the highest efficiency. The results of this scenario, which is the optimal one, are shown in Figs. 20 and 21. 


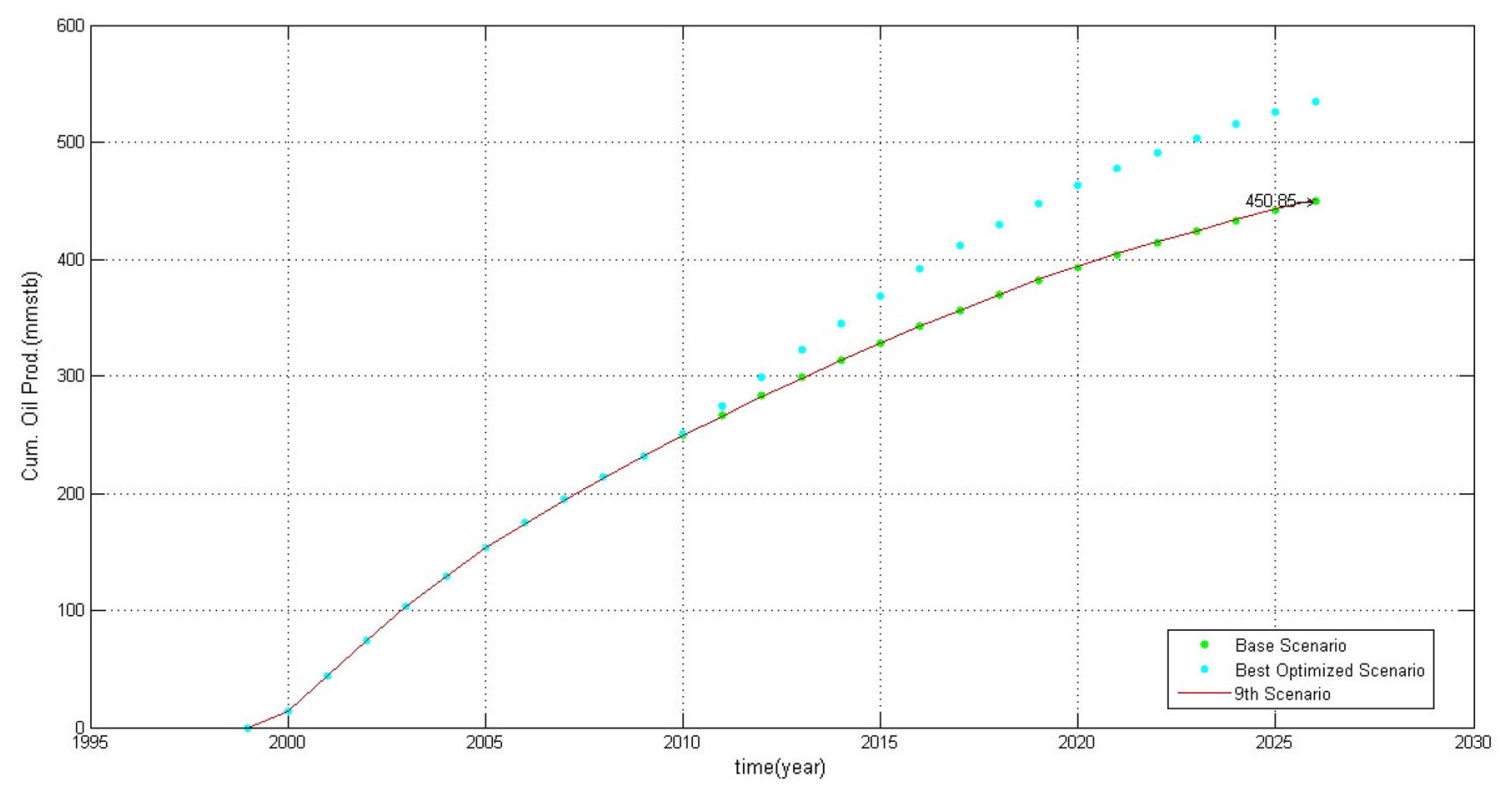

Fig. 18 Cumulative oil production of ninth scenario

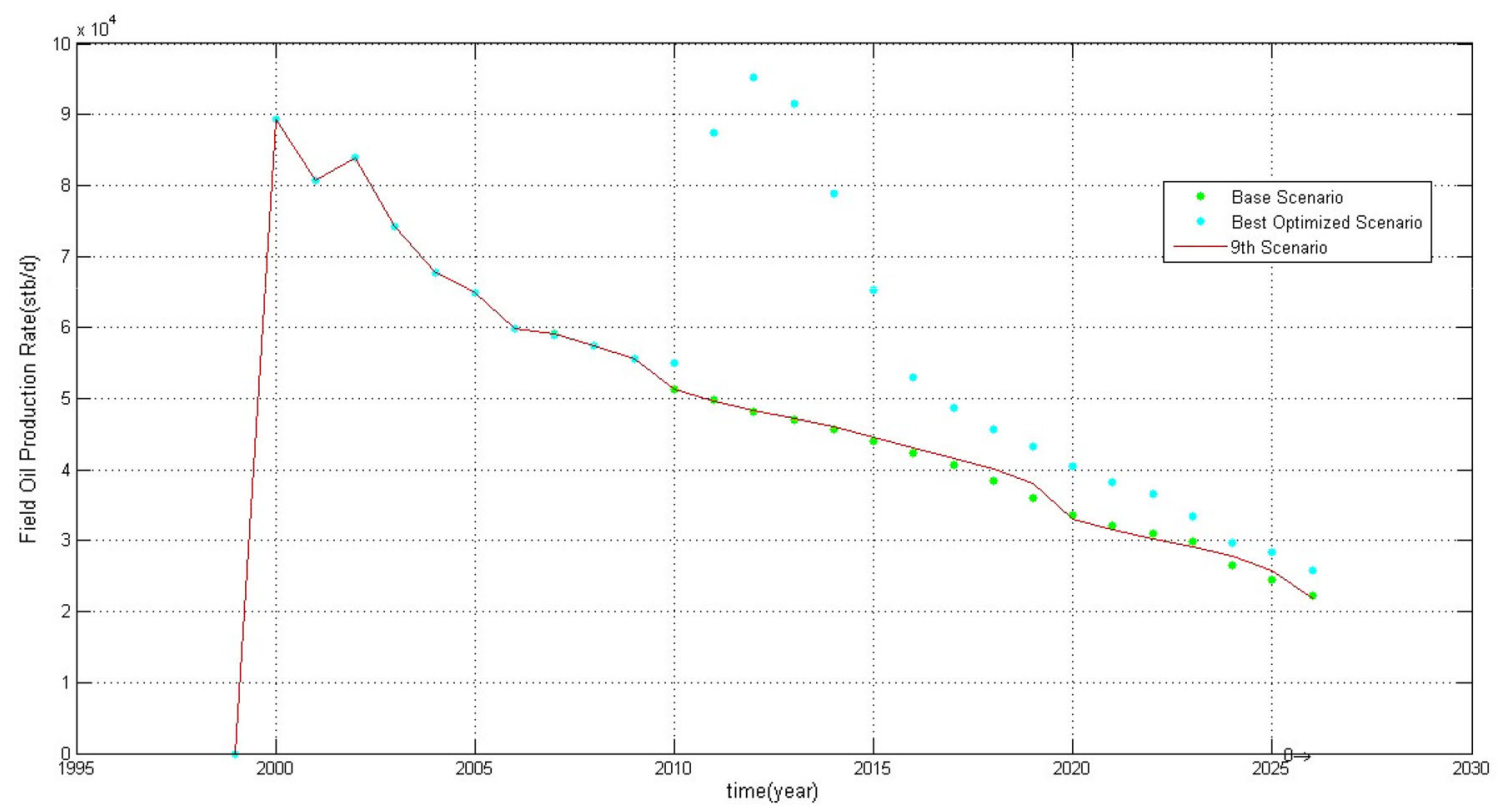

Fig. 19 Field production rate of ninth scenario

\section{Overall discussion}

Cumulative oil production and recovery factor of all the scenarios are compared in Figs. 22 and 23. Among all separate factors, drilling new production wells is the best one; however, even in this case the difference with the optimized scenario is high, which means that optimization plan should not be concentrated only on one of the factors influencing the oil production. Some of the noticeable results are as follows:
- Installation of down-hole pumps in this field is highly recommended as it increases the field oil recovery by a factor of 2.0.

- Water injection is an effective factor, and increasing injection rate has a positive effect on oil production; however, increase in the field injection rate from 140,000 to maximum value of $160,000 \mathrm{BBL} / \mathrm{D}$ by installation of new pump causes about 1.14 MMSTB extra oil production during the prediction period which is not an appreciable amount. 


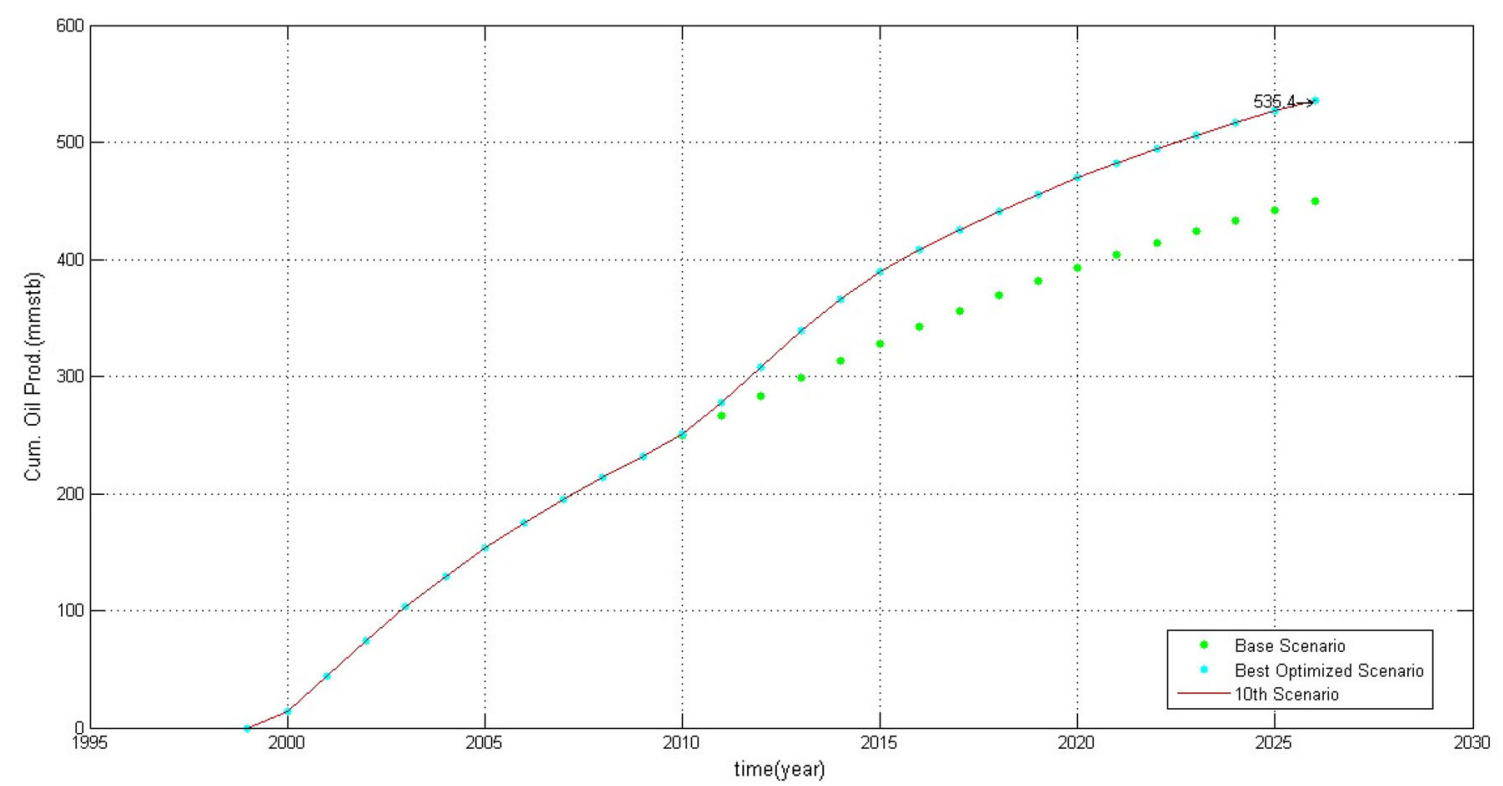

Fig. 20 Cumulative oil production of tenth scenario

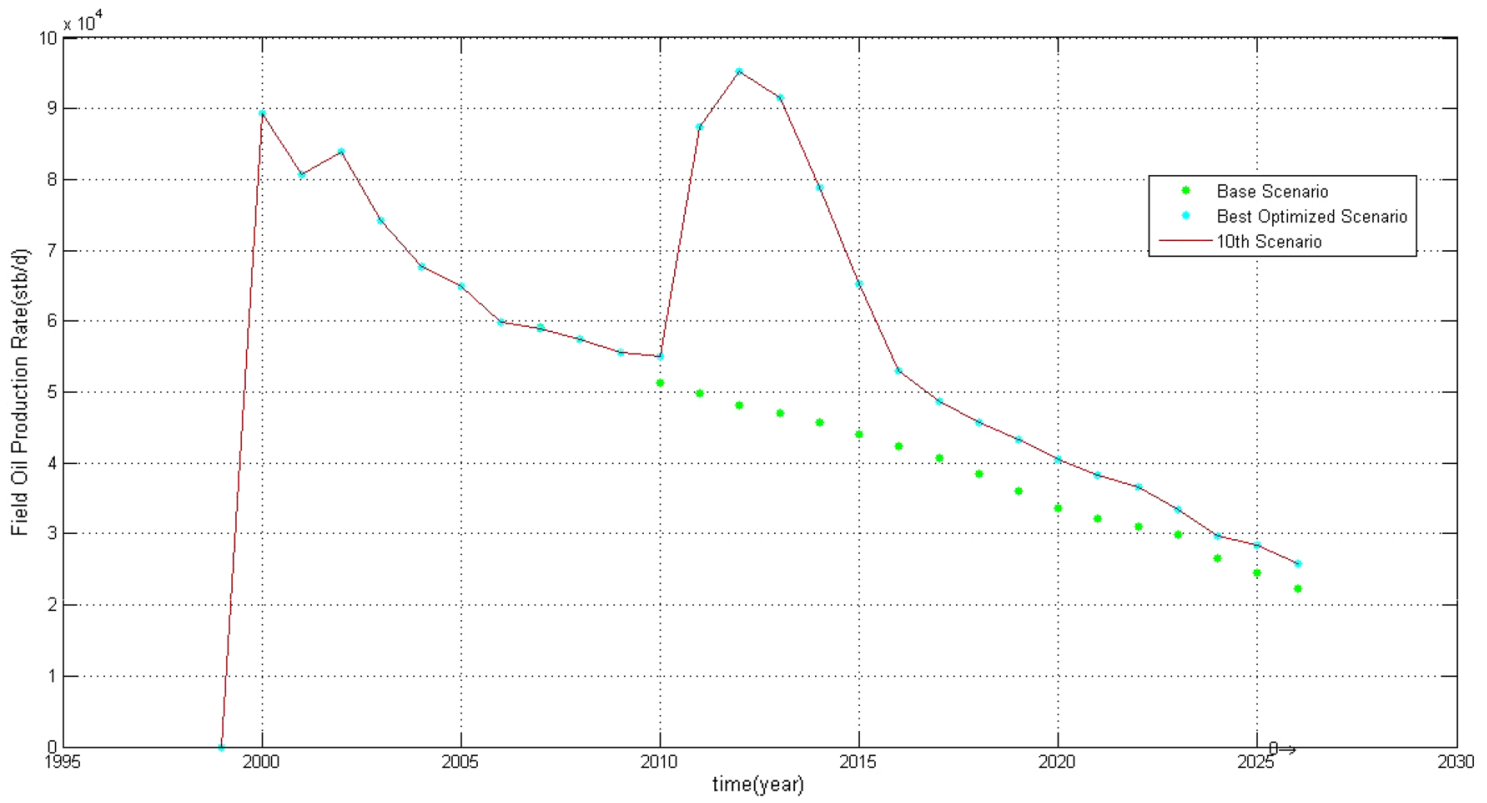

Fig. 21 Field production rate of tenth scenario

- Drilling of new wells also increases oil recovery. However, care must be taken about the location of new wells as the drainage area of the wells should not interfere each other. Additionally, the low thickness of the reservoir layer at central area of the field must be carefully considered. It has a significant impact on the oil production from the field such that it increases the field oil recovery from 30.44 to 34.97 (4.5\% for case 8e).

- Installation of down-hole pumps has a very positive impact on the oil recovery.
- Among all these factors gas injection seems to have the least effect on recovery factor; therefore it's not suggested.

\section{Conclusions}

Investigation of this field in the Middle East shows that among different factors affecting oil production such as artificial lift model, optimizing water injection flow rate, 


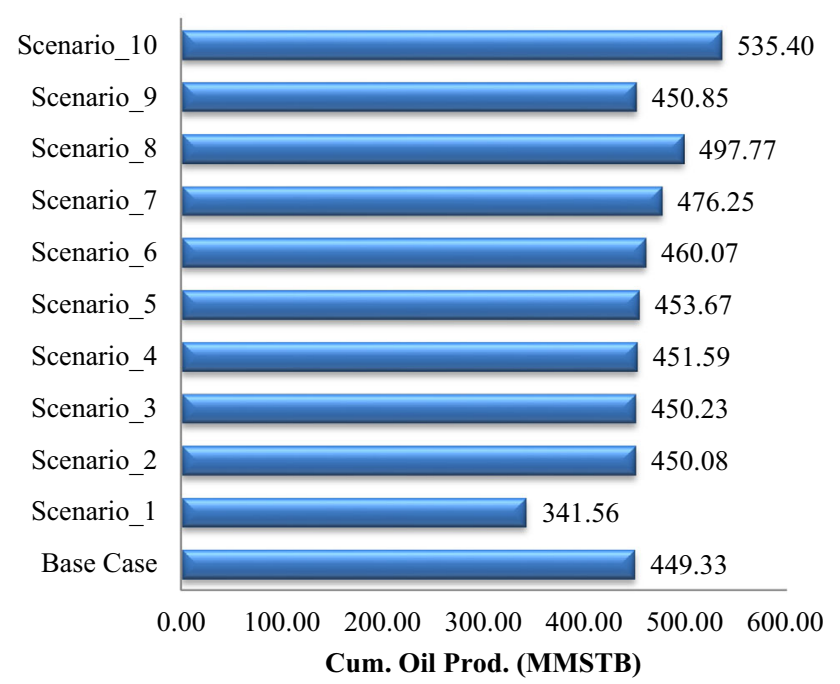

Fig. 22 Comparison of oil productions in different scenarios

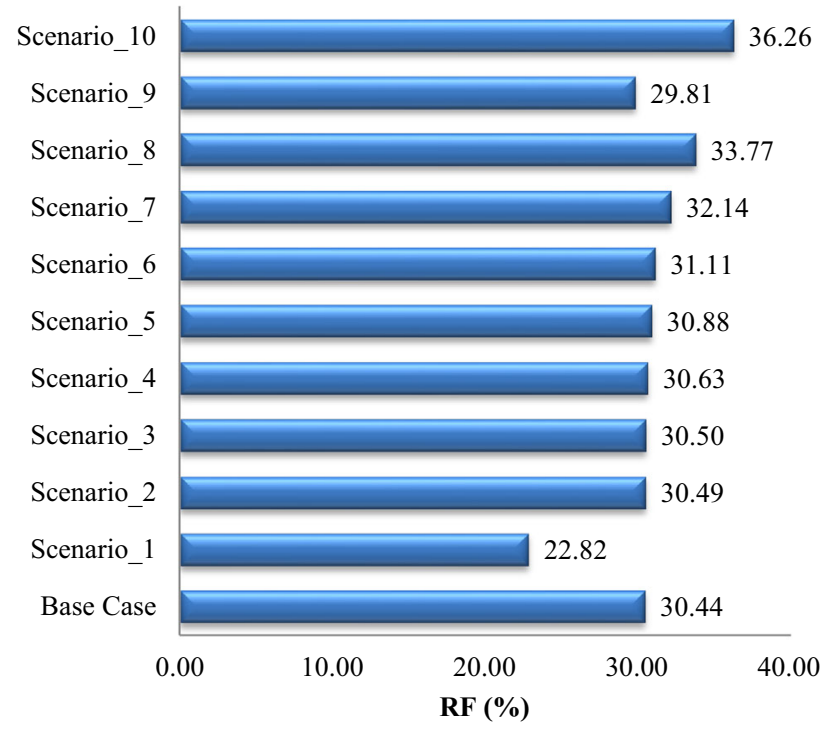

Fig. 23 Comparison of recovery factors in different scenarios

drilling new producing and injecting wells, and gas injection, drilling new production wells is the most influencing one; however, even in this case the difference in cumulative oil production between this case and the optimized scenario is high.

To prove this, a case study characterized by a complex optimization scenario has been selected. Variables, constraints, and items are taken and selected considering the actual behavior of the field. Models have been tuned and used to manage and optimize oil production in this field.

The effect of water injector is also crucial, because if they are removed from the production plan, maximum oil production will reduce to $64 \%$ of the optimized plan.
In this field, gas injection is the least effective method of increasing oil production; therefore, this method is not suggested.

Open Access This article is distributed under the terms of the Creative Commons Attribution 4.0 International License (http:// creativecommons.org/licenses/by/4.0/), which permits unrestricted use, distribution, and reproduction in any medium, provided you give appropriate credit to the original author(s) and the source, provide a link to the Creative Commons license, and indicate if changes were made.

\section{References}

Abbasi S, Tavakkolian M, Shahrabadi A (2010) Investigation of effect of gas injection pressure on oil recovery accompanying $\mathrm{CO}_{2}$ increasing in injection gas composition. In: Nigeria annual international conference and exhibition. Society of Petroleum Engineers

Alhuthali A, Oyerinde A, Datta-Gupta A (2007) Optimal waterflood management using rate control. SPE Reserv Eval Eng 10:539-551

Almeida LF, Tupac YJ, Pacheco MAC, Vellasco MMBR, Lazo JGL (2007) Evolutionary optimization of smart-wells control under technical uncertainties. In: Latin American \& Caribbean petroleum engineering conference. Society of Petroleum Engineers

Barnes D, Humphrey K, Muellenberg L (1990) A production optimization system for western Prudhoe Bay Field, Alaska. In: SPE annual technical conference and exhibition. Society of Petroleum Engineers,

Grinestaff G (1999) Waterflood pattern allocations: quantifying the injector to producer relationship with streamline simulation. In: SPE western regional meeting. Society of Petroleum Engineers

Jansen J (2011) Adjoint-based optimization of multi-phase flow through porous media-a review. Comput Fluids 46:40-51

Jaramillo OJ, Romero R, Lucuara G, Ortega A, Milne AW, Rodrigues E (2010) Combining stimulation and water control in highwater-cut wells. In: SPE international symposium and exhibition on formation damage control. Society of Petroleum Engineers

Kalam MZ, Negahban S, Al-Rawahi AS, Al Hosani I (2011) Miscible gas injection tests in carbonates and its impact on field development. In: SPE reservoir characterisation and simulation conference and exhibition. Society of Petroleum Engineers

Liu F, Mendel JM, Nejad AM (2009) Forecasting injector/producer relationships from production and injection rates using an extended Kalman filter. SPE J 14:653-664

Lo K, Starley G, Holden C (1995) Application of linear programming to reservoir development evaluations. SPE Reserv Eng 10:52-58

O'Neil RK (1976) Application and selection of electric submergible pumps. In: SPE rocky mountain regional meeting. Society of Petroleum Engineers

Palsson B, Davies D, Todd A, Somerville J (2003) Water injection optimized with statistical methods. In: SPE annual technical conference and exhibition. Society of Petroleum Engineers

Ragavanpillai G (2012) Oil production optimization for fields with sensitive wells and gas handling limitation. In: Abu Dhabi international petroleum conference and exhibition. Society of Petroleum Engineers

Stoisits R, Scherer P, Schmidt S (1994) Gas optimization at the Kuparuk river field. In: SPE annual technical conference and exhibition. Society of Petroleum Engineers 
Stoisits R, Crawford K, MacAllister D, McCormack M, Lawal A, Ogbe D (1999) Production optimization at the Kuparuk river field utilizing neural networks and genetic algorithms. In: SPE mid-continent operations symposium, pp 391-399

Sudaryanto B, Yortsos YC (2000) Optimization of fluid front dynamics in porous media using rate control. I. Equal mobility fluids. Phys Fluids 12:1656-1670 (1994-present)

Tarr CM, Heuer GJ (1962) Factors influencing the optimum time to start water injection. In: SPE secondary recovery symposium. Society of Petroleum Engineers

Thakur GC (1996) What is reservoir management? J Petrol Technol 48:520-525
Tunio SQ, Tunio AH, Ghirano NA, El Adawy ZM (2011) Comparison of different enhanced oil recovery techniques for better oil productivity. Int J Appl Sci Technol 1:1-11

Waddell J, Berthelet RA (2008) Novel approach to high water cut measurement in a mature oil field. In: Abu Dhabi international petroleum exhibition and conference. Society of Petroleum Engineers

Zou C, Chang Y, Wang G, Lan L (2011) Calculation on a reasonable production/injection well ratio in waterflooding oilfields. Petrol Explor Dev 38:211-215 